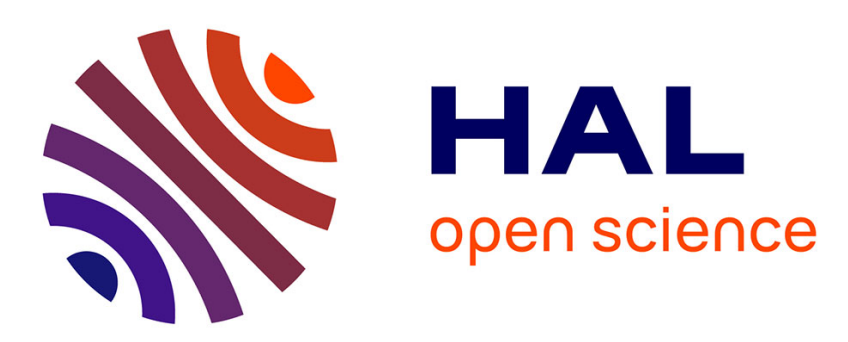

\title{
Digital image correlation of metal nanofilms on SU-8 for flexible electronics and MEMS
}

Thierry Roland, S. Arscott, Laurent Sabatier, Lionel Buchaillot, Eric

Charkaluk

\section{- To cite this version:}

Thierry Roland, S. Arscott, Laurent Sabatier, Lionel Buchaillot, Eric Charkaluk. Digital image correlation of metal nanofilms on SU-8 for flexible electronics and MEMS. Journal of Micromechanics and Microengineering, 2011, 21 (12), pp.125005. 10.1088/0960-1317/21/12/125005 . hal-00740993

\section{HAL Id: hal-00740993 \\ https://hal.science/hal-00740993}

Submitted on 23 Aug 2021

HAL is a multi-disciplinary open access archive for the deposit and dissemination of scientific research documents, whether they are published or not. The documents may come from teaching and research institutions in France or abroad, or from public or private research centers.
L'archive ouverte pluridisciplinaire HAL, est destinée au dépôt et à la diffusion de documents scientifiques de niveau recherche, publiés ou non, émanant des établissements d'enseignement et de recherche français ou étrangers, des laboratoires publics ou privés.

\section{(c)(1)}

Distributed under a Creative Commons Attribution| 4.0 International License 


\title{
Digital image correlation of metal nanofilms on $S U-8$ for flexible electronics and MEMS
}

\author{
Thierry Roland $^{1,2}$, Steve Arscott ${ }^{3}$, Laurent Sabatier $^{2}$, Lionel Buchaillot $^{3}$ \\ and Eric Charkaluk ${ }^{2}$ \\ ${ }^{1}$ INSA de Strasbourg, ICS UPR 22 CNRS, 67084 Strasbourg, France \\ ${ }^{2}$ Laboratoire de Mécanique de Lille (LML), UMR CNRS 8107, Ecole Centrale de Lille, \\ 59651 Villeneuve d'Ascq cedex, France \\ ${ }^{3}$ Institut d'Electronique de Microélectronique et de Nanotechnologie (IEMN), UMR CNRS 8520, \\ NAM6, 59652 Villeneuve d'Ascq cedex, France \\ E-mail: thierry.roland@insa-strasbourg.fr and steve.arscott@iemn.univ-lille1.fr
}

\begin{abstract}
This paper presents strain measurements using digital image correlation of common microelectronic metal nanofilms deposited onto a polymer substrate $(S U-8)$, which has applications in flexible electronics and nano/microsystems reliability analysis. The novel experimental method is based on digital image correlation coupled with microtensile test apparatus for the in situ investigation of the deformation behaviour of the deposited thin films under uniaxial tensile loading. One of the key features of the method is the real-time two-dimensional strain field measurements on a bare thin film surface, during the deformation process, without any initial speckle or grid deposition. The outstanding performances of the method, having a spatial resolution of $0.7 \mu \mathrm{m}$, allow one to envisage further studies related to the understanding of the mechanical behaviour of such thin films and, in particular, the damage localization process.
\end{abstract}

\section{Introduction}

It is becoming clear that flexible electronics [1-3] will have a major impact in applications ranging from flexible screens and touch pads to nano/microelectromechanical systems such as strain gauges. Such systems, despite the possibility of hybrid manufacturing technologies, will still require conductive thin interconnections for devices that will be subjected to large mechanical strains (up to several tens of percent). Thus, knowledge of the mechanical behaviour and possible damage of such thin films is of great interest.

Plastic deformation mechanisms (for bulk metals) are well understood and are known to be predominant due to the motion of lattice dislocations (glide). In contrast, when the metal thickness is reduced down to a critical size, typically of the order of less than a micrometre, these mechanisms change $[4,5]$ and new mechanisms can be observed, such as high mechanical stresses in consequence of confined plastic deformations [6], which also lead to fragility. As an example, in the 1990s it was a real surprise to discover that silicon is subject to fatigue when it is in the form of a thin film, whereas it is fragile in its bulk state (no dislocation activity at the ambient) [7]. In the case of metal films on the polymer substrate, used in flexible electronic devices [8], electronic textiles [9] and bioengineering [10], the difference between the mechanical properties of thin films and bulk counterparts may, furthermore, be attributed to differences in microstructure due to the fabrication method, size effects and possible substrate effects [11]. Size effects are also important in terms of materials' physical properties, e.g., giant piezoresistance $[12,13]$.

Thus, with the ongoing trend of miniaturization in thin film technology, it will become necessary to explore these sizedependent physical properties to warrant safety, functionality 




Figure 1. Schematic of data-acquisition and image processing system and typical tensile sample used in this study: Pt films/SU-8 substrate.

and reliability of the applications. A number of studies have been performed based on X-ray diffraction (XRD) [14], vibration and bending techniques [15] or nanoindentation [16], but only a few investigations have been concerned with the determination of mechanical properties of thin films through direct tensile testing [17, 18] and even less regarding their deformation mechanisms.

This study aims to investigate the damage micromechanisms of thin films on a flexible substrate observed in real time, with an in situ microscope device, during tensile test performed at room temperature. The originality of the method comes from the use of a recently developed technique of digital image correlation (DIC) directly applied at the microstrutural scale without any previous coating [19]. This is one of the original aspects of this work in comparison with the classical use of DIC. Owing to the presence of a polymer substrate, displacement and strain fields are calculated up to the final failure of the metal film and, through their gradients, probable microcrack initiation sites are indicated. Due to the good spatial resolution (close to $0.7 \mu \mathrm{m}$ ), it is thus possible to precisely follow the evolution of the damage micromechanisms. Although only a static loading is considered here, this technique can also be applied in dynamic mode.

Two common microelectronic metal thin films of gold (Au) and platinum (Pt) deposited onto the $S U-8$ polymer substrate were chosen as materials of interest. The first step concerns the feasibility of the image correlation directly on the raw surface and tests were conducted on both metallic films, Au and Pt. Since most of mechanical studies about the $S U-8$ substrate are concerned with the relationship between processing parameters (curing time and irradiation dose) and its subsequent mechanical performances [20-22], information about damage and failure mechanisms of thin films deposited on such a substrate is another interest of the present study, and might help to ensure the functionality of the microsystems based on these materials. The second step concerns therefore the analysis of damage mechanisms, and the study focuses on Pt films. Displacement and strain fields are then analysed and compared to the evolution of the damage observed during the loading.

\section{Experimental procedure}

\subsection{Materials and samples}

$\mathrm{Au}$ and $\mathrm{Pt}$ thin films deposited on a negative photoresist $S U-8$ substrate were chosen as experimental materials for their interest in microelectronics and microsystems (MEMS). Specifically, $S U-8$ is a photolithographic polymer with a wide range of applications in microtechnology having advantages such as a high aspect ratio and physical robustness [23, 24]. Moreover, it features water insolubility, biocompatibility and chemical durability after polymerization which makes it a material of choice for the design of functional-mechanical structures in MEMS. The authors have previously developed lift-off techniques for free standing $S U-8$ films [25], fabricated microchannels [22] and microfluidic devices [26], and also deposited metal circuits on $S U-8$ layers [27].

Dog-bone tensile testing samples of $S U-8$ with a gauge length of $20 \mathrm{~mm}$, a gauge width of $5 \mathrm{~mm}$ and a thickness of $200 \mu \mathrm{m}$ were prepared using $S U-8$ lift-off techniques [25]. Then thin metal films ( $\mathrm{Au}$ and $\mathrm{Pt}$ ) of different sizes were deposited onto these polymeric substrates using electron-beam evaporation and a specifically designed mechanical masque. The thicknesses of the Au and Pt films were 50 and $100 \mathrm{~nm}$, respectively. Figure 1 shows an optical image of a typical studied tensile sample as well as the apparatus setup. 

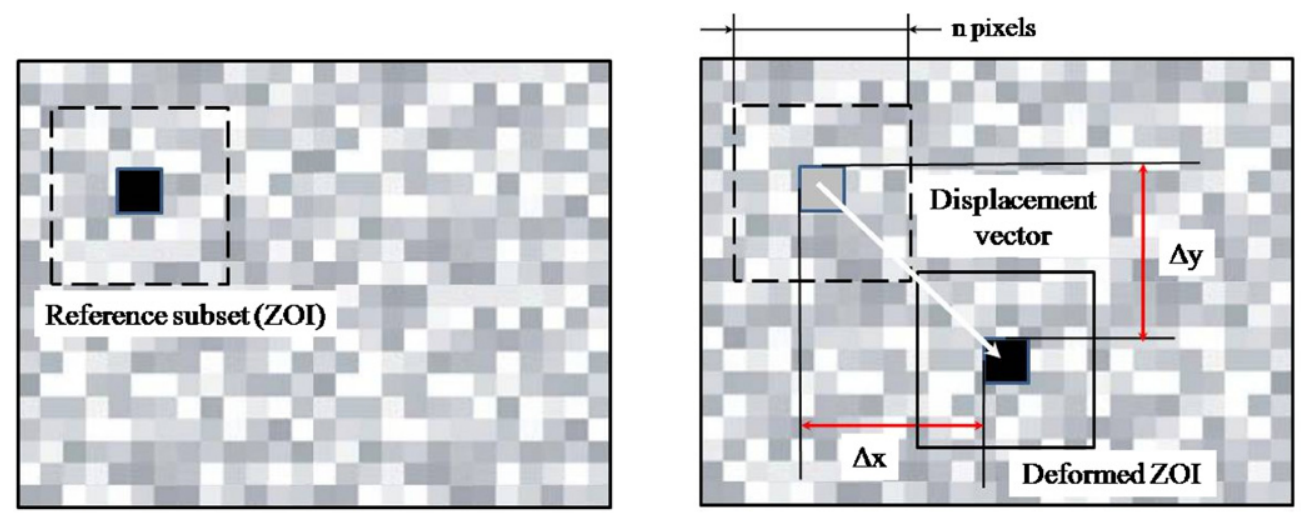

Figure 2. Displacement evaluation by cross-correlation algorithm; (left) detail of a reference, (right) detail of the deformed image.

\subsection{Tensile tests}

The tensile test was conducted on a specifically developed microtensile testing machine able to apply tensile or compressive load through a $2 \mathrm{kN}$ load cell. Crosshead displacement was controlled with an LVDT either in an automatic or manual way with a rate of $1 \mu \mathrm{m} \mathrm{s} \mathrm{s}^{-1}$ or $5 \mu \mathrm{m} \mathrm{s}^{-1}$. To carefully adjust the alignment and horizontality of the mounted specimen, a special design of grip was previously made using the computer-assisted design and prototyping. Control and data acquisition were performed using a program developed on Labview software. To study the feasibility of the present experimental method and the DIC directly on raw surfaces, both films ( $\mathrm{Au}$ and $\mathrm{Pt}$ ) were studied.

Each sample was loaded in tension up to substrate failure with an extension velocity of $1.0 \mu \mathrm{m} \mathrm{s}^{-1}$. Surface damage and its evolution were studied at successive strain intervals during tensile displacement. Observations were carried out with an in situ microscope device composed of a 10 bit CCD camera, a coaxial lens and a zoom lens. This assembly was mounted on micrometric tables to allow translation along the three spatial axes and rotation around the vertical axis. Regarding the environmental vibration problems encountered at such observation scales, the smallest zone observable in real time during tensile loading was $120 \times 90 \mu \mathrm{m}^{2}$. This observable zone was sufficient to reveal the premises of damage of the studied films at the microstructural scale and large enough to follow its evolution and the subsequent heterogeneities up to the complete failure of the specimen. The image size represents $1368 \times 1024$ pixels; a representative size of 1 pixel of about $90 \mathrm{~nm}$ is thus reached. Regarding the spatial resolution, this one is defined through the Rayleigh criterion. According to this Rayleigh criterion, it is not able to distinguish the images of the two objects separated by a distance inferior to the half-wavelength of the emission source because of some diffraction problems. In the case of lighting in the visible domain, as done in this study, the limit resolution is $0.4 \mu \mathrm{m}$. Since the zoom lens owns a defined opening, its resolution $p$ can be determined by using the Rayleigh criterion as $p=\lambda /(2 n \sin U)$, where $\lambda$ is the wavelength of the used light and $n \sin U$ is the opening constant of the zoom lens. Thus, with an opening of 0.55 , the resolution is $0.7 \mu \mathrm{m}$.

A key point of the study is to precisely measure the local strain at a microscopic level within the films; thus, a novel strain mapping technique has been used based on the analysis of natural texture using DIC software (CorreliQ4) [28, 29].

\subsection{Acquisition, digital image correlation}

Direct film testing through conventional methods, such as those using strain gauges, is difficult to implement due to the presence of the substrate. Also, one challenge that remains in thin film technology, and more generally in microfabrication of components, is the characterization of performances (usually microstructural) at reduced scales. In this context, Moiré techniques combined with AFM have shown some results [30]; however, the experimental setup is quite cumbersome and the requirement of a fine grating leads to difficulties in the fabrication process and high costs. In addition, this method is not adapted for thin films studies. Techniques of image correlation seem more convenient for the observation of deformation processes in a variety of materials in real time. Previously developed in the 1980 s by Sutton et al at the University of South Carolina, the DIC technique has since known as a wide development [31]. Compared to common strain measurement methods, the DIC method has the advantages to enable local information to be obtained at the microscopic scale, on micromechanisms such as strain localization. Based on the computer-aided comparison of grey-scale images by means of the application of a correlation algorithm, the DIC technique, however, needs random patterns to be applied on the surface of the specimen for tracking the deformation via the comparison of the non-deformed and deformed images.

In practice, to determine the displacement field of one image with respect to a reference image, one considers a sub-image (i.e. a square region), which will be referred to as the zone of interest (ZOI) or a subset. The aim of the correlation method is to match the $\mathrm{ZOI}$ in the two images (figure 2). The displacement of one ZOI with respect to the other one is a two-dimensional shift of an intensity signal digitized by a CCD camera. For the sake of clarity, in the remainder of this section, the analysis is illustrated on onedimensional signals. To estimate a shift between two signals, one of the standard approaches utilizes a correlation function. 

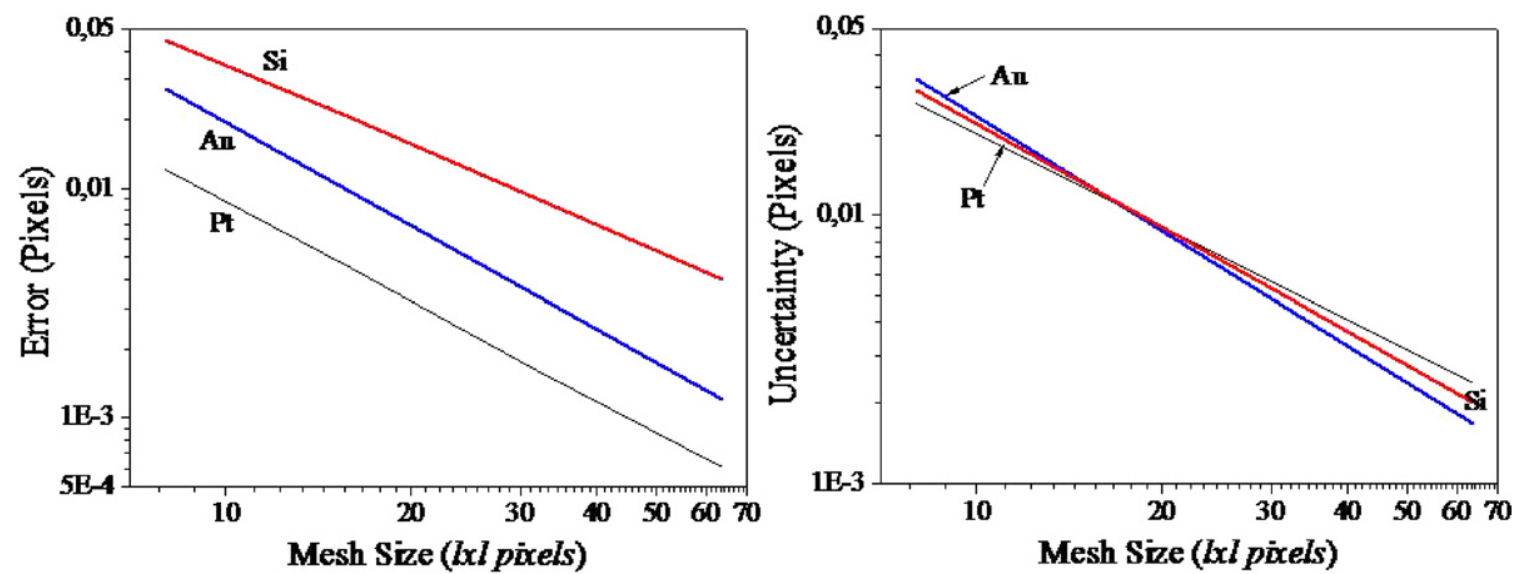

Figure 3. Standard deviation and uncertainties on calculated displacements for different mesh sizes.

One considers signals $g(\xi)$ which are merely perturbations of a shifted copy $f(\xi-\delta)$ of some reference signal $f(\xi)$ :

$$
g(\xi)=f(\xi-\delta)+b(\xi)
$$

where $\delta$ is an unknown displacement and $b(\xi)$ is a random noise. To evaluate the shift $\delta$, one may minimize the norm of the difference between $f(\xi-\delta)$ and $g(\xi)$ with respect to $\Delta$ :

$$
\min _{\Delta}\|g-f(\Delta)\|^{2} \text {. }
$$

If one chooses the usual quadratic norm $\|f\|^{2}=$ $\int_{-\infty}^{+\infty} f(\xi) \mathrm{d} \xi$, the previous minimization problem is equivalent to maximizing the quantity $h(\Delta)$ :

$$
h(\Delta)=(g * f)(\Delta)=\int_{-\infty}^{+\infty} g(\xi) f(\xi-\Delta) \mathrm{d} \xi,
$$

where $^{*}$ denotes the cross-correlation product. Furthermore, when $b$ is a white noise, the previous estimate is optimal. The computation of a cross-correlation can be performed either in the original space or in the Fourier space, by using a FFT:

$$
g * f=\sqrt{N} \mathrm{FFT}^{-1}(\mathrm{FFT}[g] \overline{\mathrm{FFT}[f]}),
$$

where the complex conjugate is overlined and $N$ is the number of samples in the Fourier transform (to use fast algorithms, it is required that $N=2^{n}$, where $n$ is an integer). The previous results can be generalized to two-dimensional situations (i.e. image matching). The use of shifting property enables one to move a signal. Let us consider the shift operator $T_{d}$ defined by

$$
\left[T_{d} f\right](\xi)=f(\xi-d),
$$

where $d$ is the shift parameter. The FFT of $T_{d} f$ becomes

$$
\operatorname{FFT}\left[T_{d} f\right]=E_{d} \operatorname{FFT}[f],
$$

where the modulation operator $E_{d}$ is defined by

$$
\left[E_{d} f\right](\xi)=\exp (-2 \pi j \mathrm{~d} \xi) f(\xi) .
$$

These two results constitute the basic tools for image correlation.

For macroscopic studies, spray painting can be used to generate the desired pattern of different grey scale (intensity) [32]. Other techniques exist based on deposited microgrids $[33,34]$. But, in the case of thin films $(<200 \mathrm{~nm})$, any externally applied pattern will automatically disturb the physical process under observation and affect the mechanical behaviour or worse, hide it. Thus, despite several creative preparations of patterns to use DIC at the microscale, among which the ones using sputtering and physical deposition techniques or deposition of fluorescent nanoparticles [35], the application of the DIC technique on thin films remains an open subject. In addition, optical systems allowing high magnification need to be used.

In this work, the recently developed MATLAB-based DIC program CORRELIQ4, allowed us to directly use microstructural surface features of thin films as a "natural speckle pattern'; this correlation method is described elsewhere [28].

\section{Results and discussions}

\subsection{Feasibility and performances of DIC on thin films}

Using a mesh size of 32 pixels, as the subdivision of the digital images (ZOI, see figure 2), performances of the displacement and strain field calculation in terms of accuracy and resolution were evaluated for the $\mathrm{Au}$ and $\mathrm{Pt}$ thin films. The accuracy depends obviously on the software itself but also on the images through their grey-level distribution, the camera dynamic range, the specimen lighting and the image resolution. A typical image used in this study covers an area of $150 \times 115 \mu \mathrm{m}^{2}$; a representative size of one pixel of about $0.1 \mu \mathrm{m}$ is thus obtained. Numerical shift by a known displacement ranging from 0 to 1 pixel with 0.1 pixel increments allowed us to define the error and standard deviation on displacements and strains calculated by comparison to their known prescribed values. Maximum uncertainty was reached for a prescribed displacement of 0.5 pixel and its value is less than 0.004 pixel, which corresponds in the present case to 0.36 micrometers. Figure 3 presents displacement uncertainties and errors as a function of the different mesh sizes and for the two tested thin films. Displacement (and strain) uncertainties decrease when the mesh size increases because of the related number of measurement points. In subset-based DIC, the users must manually select a subset (ZOI) size varying from several pixels to even more than 100 pixels. Since the subset size 
Table 1. Summary of the accuracy obtained with some experiments using SEM compared to this work.

\begin{tabular}{lllll}
\hline $\begin{array}{l}\text { Optical } \\
\text { means }\end{array}$ & $\begin{array}{l}\text { Structure } \\
\text { shape }\end{array}$ & $\begin{array}{l}\text { Spatial } \\
\text { resolution } \\
(\mu \mathrm{m})\end{array}$ & $\begin{array}{l}\text { Accuracy } \\
\text { (pixel) }\end{array}$ & $\begin{array}{l}\text { Uncertainty } \\
\text { (pixel) }\end{array}$ \\
\hline SEM [28] & Thin films & 0.179 & $0.026-0.01$ & \\
SEM [31] & Bulk & 0.2 & 0,006 & 0.025 \\
SEM [31] & Bulk & 0.3 & 0,012 & \\
Present work & Thin films & 0.7 & 0.006 & 0.004 \\
\hline
\end{tabular}

directly determines the area of the subset being used to track the displacements between the reference and target subsets, it is found to be critical to the accuracy of the measured displacements. To achieve reliable correlation analyses in DIC, the size of a subset should be large enough so that there is sufficiently distinctive intensity pattern contained in the subset to distinguish itself from other subsets. On the other hand, however, it is noted that the underlying deformation field of a small subset can readily and accurately be approximated by the first- or second-order subset shape function, whereas a larger subset size normally leads to large errors in the approximation of the underlying deformations.

Performances of the present experimental procedure equal those obtained with heavier instruments such as SEM [36] or AFM [37]. In fact, an accuracy of 0.026 pixels has been reported for the resolution of $0.179 \mu \mathrm{m}$ with a SEM device and of 0.01 pixels when a special pattern is developed (photolithography) [36]. Table 1 summarizes the performances reached in terms of accuracy and uncertainty by several techniques using different means of observation (magnification) combined with digital images correlation methods [38, 39]. These techniques were applied to bulk materials of classical grain size after the preparation of their surface by etching to reveal a natural pattern. In comparison with this work, it is clear that the obtained accuracy on the measured displacement is of the same level. Then, to validate the method as an example, in situ deformation mechanisms of $\mathrm{Pt}$ thin films within a conventional testing machine were studied, and damage and crack mechanisms initiation were analysed.

\subsection{Local strain measurement and possible failure mechanisms of Pt thin films on SU-8}

As numerous metal films of different sizes are deposited simultaneously on $S U-8$, depending on the relative position of the film to the substrate, the film may fracture when subjected to tension or delaminate when subjected to compression (buckling). To shorten, only results on the Pt thin film are presented here. During straining, failure behaviour was investigated in situ with an optical microscope. Figure 4 shows the progression of the damage during tensile loading through strain mapping and the related optical observations of the microstructure. The loading direction is vertical and the strain distribution is parallel to it. Unlike with electrical or acoustic detection, damage can be observed before real cracking appears as indicated by the broadening of the strained zone calculated at time $t-\delta t$. The $\delta t$ notation refers to the fact

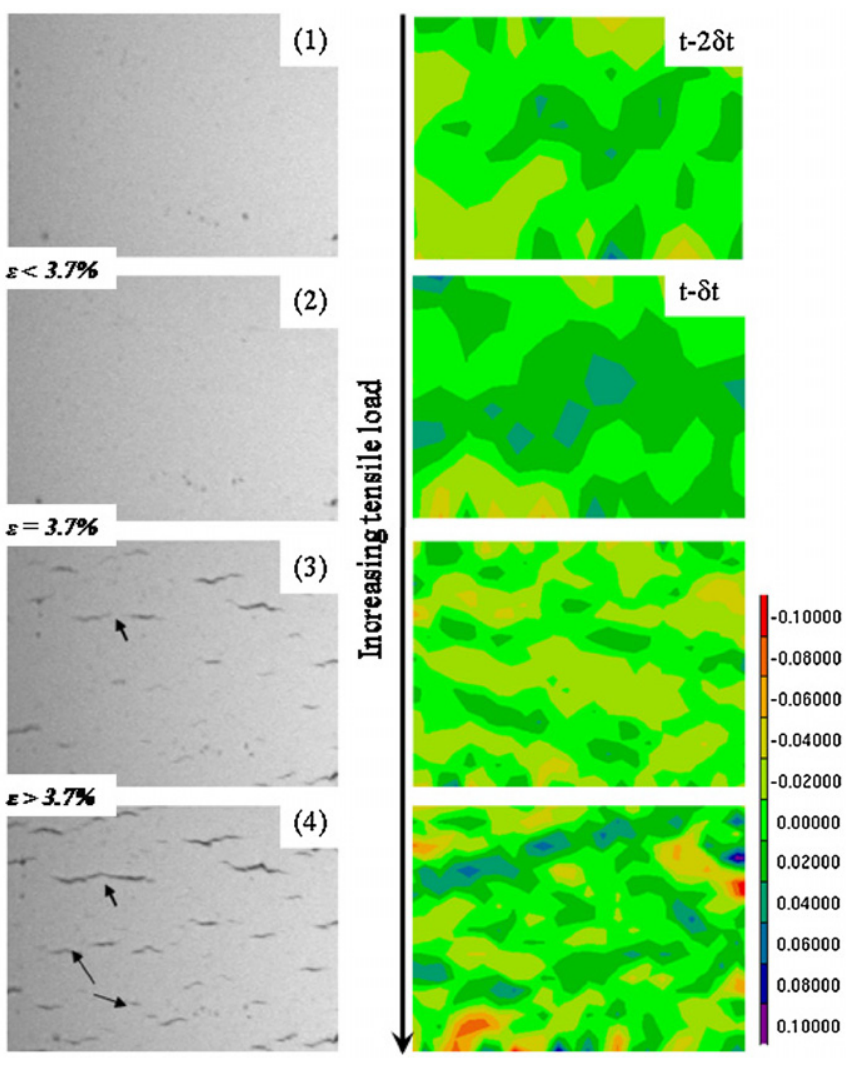

Figure 4. Evolution of the damage during tensile loading through DIC calculation. Sudden broadening of the strain field at $t-\delta t$ (corresponding to the evolution between (1) and (2)) indicates near failure of the Pt film.

that the time period between the two taken images (1) and (2) was very short. In fact, the result of digital images correlation between the optical micrographs 4(1) and (2) shown on the image annotated $t-\delta t$, clearly shows the appearance of heterogeneities within the film with some intensifying blue regions and particularly an extension of the deformed region. While nothing lets envisage some changes if one only looks at the micrographs (4(1) and (2)), this sudden broadening of the deformed zone and the heterogeneities shows local strains, within the film under tension, that exceed the average strain by a factor of 2-3; thus, they can be seen as an early indicator of the formation of cracks. Calculated from DIC, the first microcrack initiation was observed at a strain of $3.7 \%$ (mean value) at the centre of the film in the normal direction in relation to the stress direction. With increasing strain, new cracks appear, while previous cracks become intensified, as indicated by black arrows in figures 4(3) and (4). All these cracks within the film present no cross-linking, as observed in previous works $[40,41]$ and are referred to as channelling cracks. Some negative strain field regions also appeared. At the origin of these fields, a possible bending around the cracks may appear inducing compressive stress according to the direction of the localized delamination. Another reason, linked to the previous one, is that cracks relax the initial stress state. From these calculated strains, the ultimate mean strain of Pt films can be determined independently of the knowledge of the strain supported by the substrate. Such information can 

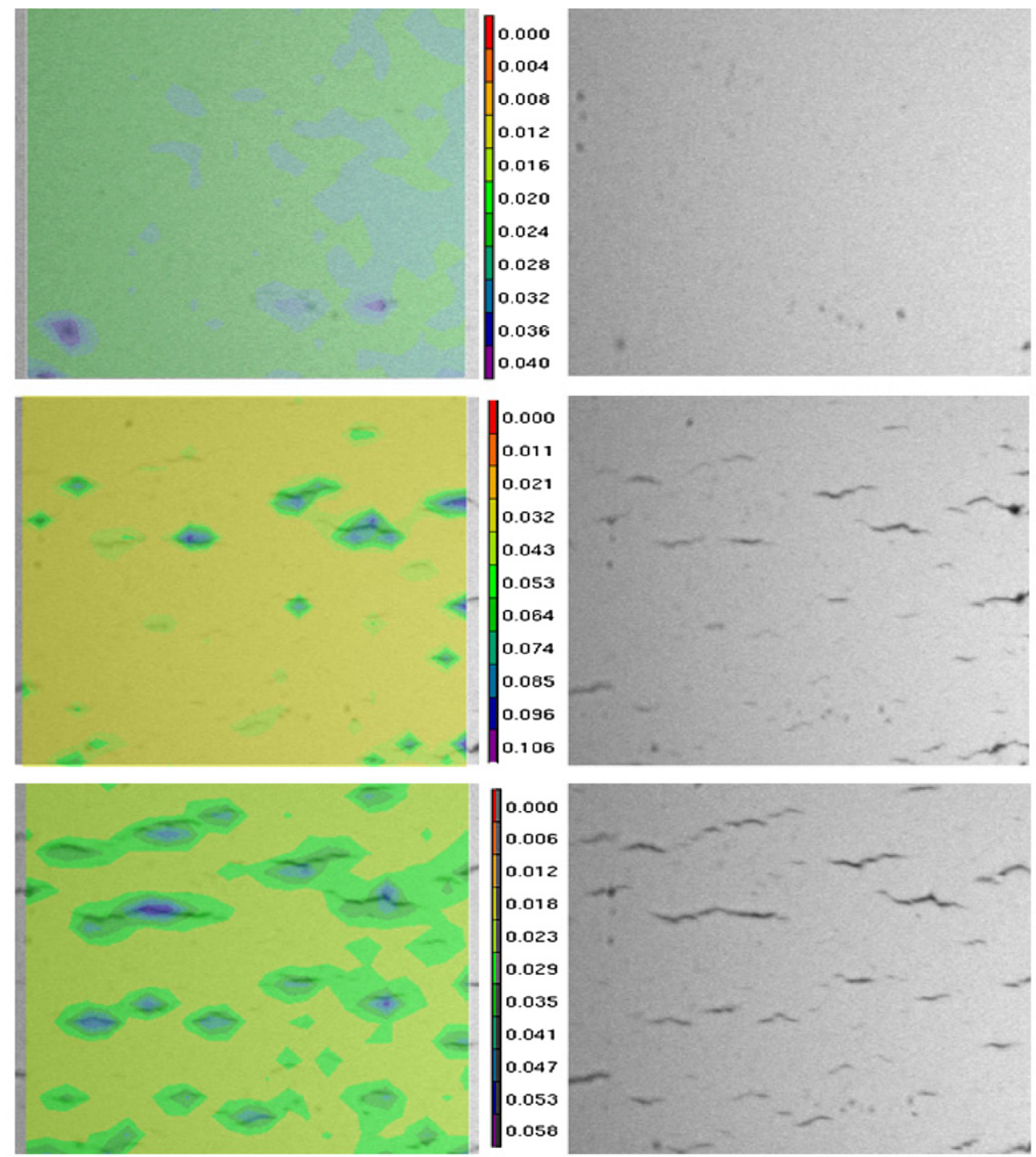

Figure 5. Accuracy of the calculated deformations shown in figure $3-$ not more than $10 \%$ error.

be particularly useful for a microsystem device designerfor instance, it might be possible to precisely determine the ultimate strain before failure for the same metallic thin film deposited on a different substrate-or still to foresee the effect of using a deposition technique instead of another (PVDCVD). At higher strains, above $3.7 \%$, channelling cracks emerge to form multiple parallel cracks all over the film. It is interesting to note that even when the ultimate strain is reached and the cracks form, the DIC can still provide accurate results as shown in figure 5. From this figure, the convergence errors are evaluated for each increment and do not exceed values of $8-9 \%$, which are usual values obtained in more conventional experiments including painting as a pattern and rather bulk materials [31, 32]. The error is less than $10 \%$ and thus the strain quantification still remains acceptable. Another remarkable aspect is that localization of the maximum error values perfectly match those of the cracks, as shown in figure 5, through the superposing of the microstructure to the calculated convergence error. This can be explained by the assumptions taken in DIC, which considers continuous kinematic fields. In the particular case of the DIC program CORRELIQ4, this continuous projection basis is similar to the one used in finite-element methods with linear or quadratic form basis function. Therefore, in practice, close to the cracks, displacement discontinuities appear leading to maximum error values. In general, to avoid this problem or at least reduce it, some filtering methods exist [42]. In the present case, this error map is particularly interesting as it indicates the discontinuities location. From figure 4, a clear distinction can be observed between images before and after crack appearance; after cracking, the Pt thin film can still sustain the tensile load at this strain, showing a continuous adhesion of the film on the substrate. At a strain equal to $4 \%$, the substrate is broken in a glassy way, with several straight cracks crossing the entire specimen and leading to its complete failure. At this step, the convergence of the DIC calculus is no longer possible since the image texture has changed too much. Figure 6 shows individual typical microcracks observed by SEM on the Pt thin film and a straight crack at the edge of the tensile specimen coming from the substrate and crossing 




Figure 6. SEM observation of the failure mode of the specimen, microcracks (1) formed at the first step followed by cracks of the substrate (2) are observable (inset is a zoom).

the thin film. Compared to known mechanical properties of $S U-8$, the total elongation of $4 \%$ is rather expected [20]. In fact, depending on the processing parameters and conditions, it has been reported that mechanical properties of $S U-8$ can vary between 0.7 and $2.7 \mathrm{GPa}$ for Young's modulus, between 14.6 and $52.5 \mathrm{MPa}$ for the strength, and between $1.8 \%$ and $7.5 \%$ for the elongation $[20,43]$.

Thus, the present method in comparison to previous works has the advantage to use quite common and classical instruments, but above all, it allows measuring the distribution of the local strain at a microscopic level showing heterogeneities of the strain within the thin films.

With respect to the results here, measuring the local strain distribution of thin films at a microscopic level reveals the detailed information of the damage evolution leading to failure. This knowledge is essential in the MEMS design; for instance, in the earlier mentioned study for monitoring electrical impedance in living tissues [44], where microprobes consisting of a $160 \mu \mathrm{m}$ thick $S U-8$ substrate containing a four-planar surface area $(300 \mu \mathrm{m} \times 300 \mu \mathrm{m})$ of $\mathrm{Pt}$ have been developed, it could be necessary to know how much deformation the Pt electrodes can withstand before failure or how damage occurs in fatigue. It also appears that only the mechanical properties of the $S U-8$ substrate are characterized in this study, while from the present study, it is shown that Pt thin films may crack before the substrate. Knowledge of the failure scenario could ensure the electrical reliability of the component. Indirectly, these aspects could also help in the choice of the processing parameters and the conditions of deposition, especially because properties of flexible substrates,
Table 2. Ultimate tensile strain for Si, PDMS and $S U-8$ as a substrate.

\begin{tabular}{ll}
\hline Substrate & Ultimate tensile strain \\
\hline Silicon & Fragile-no ductility [7] \\
$S U-8$ & 1.8 to $7.5 \%(20,43$, present study) \\
PDMS & $>100 \%$ (present study $\left.{ }^{\mathrm{a}}\right)$ \\
\hline
\end{tabular}

${ }^{a}$ Measurements in the laboratory with videoextensometry.

plastics and polymers such as $S U-8$ depend on processing parameters. Table 2 summarizes our results.

Fatigue of thin films is another aspect to be taken into account for the development of MEMS, especially as they usually show some atypical behaviour compared to their bulk counterparts.

However, it should be noted that especially designed test machines are needed to test such thin films requiring cumbersome instrumentation. Among them, some electrostatic actuators or special bending experiments can be quoted in the case of free-standing thin films and microtensile testing machine when a substrate is used [45-48]. In addition, in all the cases, the measurement of the strain at this reduced scale remains a challenging problem and here again, to do so, special instruments have been used. XRD and other optical systems based on interferometry theory were among the most relevant $[46,49]$. With these instruments, only the mean value of the strain was obtained as a strain gauge would do it for more classical experiments.

\section{Conclusion}

Understanding the material properties of thin nanofilms and their relationship to processing parameters is of prime importance for the newly developed field of flexible electronics in the context of microelectronics and microsystems. From this study, feasibility of the flexible electronic component based on the $S U-8$ substrate has been proven through a reached ultimate strain of the order of $4 \%$. $S U-8$ can thus be accepted as an alternative material between $\mathrm{Si}$ (fragile) and PDMS to design flexible components.

Compared to DIC dedicated to the microscale, and including heavy instruments as SEM or AFM, the present method is flexible for many environmental works.

It has been shown that the $\mu$-DIC technique can be applied to nanothick metallic films with a resolution compatible with the scale of the studied objects. The analyses of the heterogeneous strain allow better quantification of the origin and evolution of damage.

Also, beyond the possibilities that offer the present technique for analysing the mechanical behaviour of materials during mechanical tests and particularly for studies in fatigue, it appears as a promising technique to identify strain and damage physical mechanisms on the microstructural scale in order to help in defining a constitutive law necessary for future numerical simulation such as finite-element modelling in nanomaterials (design). Finally, very few studies on the failure strain and more generally on the failure modes of this 
type of materials as deposited on polymer substrate have been done, which reinforced the interest of this study.

\section{Acknowledgment}

This work was initiated within the framework of a Postdoctoral Research Program supported by the CNRS (French National Research Center).

\section{References}

[1] Kim D H 2008 Science 320507

[2] Ahn B Y 2009 Science 323 1590-3

[3] Hamers R J 2001 Nature 412489

[4] Van Swygenhoven H 2002 Science 296 66-7

[5] Yamakov V, Wolf D, Phillpot S R, Mukherjee A K and Gleiter H 2002 Nat. Mater. 1 45-8

[6] Jia D, Ramesh K T and Ma E 2003 Acta Mater. 51 3495-509

[7] Alsem D H, Stach E A, Muhlstein C L and Ritchie R O 2005 Appl. Phys. Lett. 86041914

[8] Li T and Suo Z 2006 Acta Mater. 432351

[9] Bonderover E and Wagner S 2004 Electron Device Lett. 25295

[10] Mendelsohn J, Yang SY, Hiller J, Hochbaum A and Rubner M F 2003 Biomacromolecules 496

[11] Cao Y, Allameh S, Nankivil D, Sethiaraj S, Otiti T and Soboyejo W 2006 Mater. Sci. Technol. 427232

[12] He R and Yang P 2006 Nature Nanotechnol. 1 42-6

[13] Milne J, Rowe A C H, Arscott S and Renner C 2010 Phys. Rev. Lett. 105226802

[14] Goudeau P, Renault P O, Villain P, Coupeau C, Pelosin V, Boubeker B, Badawi K F, Thiaudiere D and Gailhanou M 2001 Thin Solid Films 496 398-9

[15] Harms U, Kempen L and Neuhauser H 1998 Thin Solid Films 323153

[16] Bucaille J L, Stauss S, Schwaller P and Michler J 2004 Thin Solid Films 239 447-8

[17] Sharpe W N Jr, Yuan B and Edwards R L 1997 J. Microelectromech. Syst. 6193

[18] Faurie D, Renault P O, Le Bourhis E and Goudeau P 2006 Acta Mater. $\mathbf{5 4} 4503$

[19] El bartali A et al 2008 Fatigue Fract. Eng. Mater. Struct. 31 137-51

[20] Feng R and Farris R J 2003 J. Micromech. Microeng. 13 80-8

[21] Gaudet M, Camart J C, Buchaillot L and Arscott S 2006 Appl. Phys. Lett. 88024107

[22] Carlier J, Arscott S, Thomy V, Fourrier J C, Caron F, Camart J C, Druon C and Tabourier P 2004 Micromech. Microeng. 14619

[23] Genolet G, Brugger J, Despont M, Drechsler U, Vettiger P, De rooij N F and Anselmetti D 1999 Rev. Sci. Instrum. 702398
[24] Bogdanov A and Peredkov S 2000 Microelectron. Eng. 53493

[25] Arscott S, Garet F, Mounaix P, Duvillaret L, Coutaz J-L and Lippens D 1999 Electron. Lett. 35 243-4

[26] Arscott S, Le Gac S, Druon C, Tabourier P and Rolando C 2004 J. Micromech. Microeng. 14 310-6

[27] David T, Arscott S, Munier J-M, Akalin T, Mounaix P, Beaudin G and Lippens D 2002 IEEE Microw. Wirel. Compon. Lett. 12 281-3

[28] Hild F and Roux S 2006 Strain 4269

[29] Hild F and Roux S 2006 C. R. Mec. 33412

[30] Zhong Z W and Lu Y G 2005 J. Inter. Meas. Confederation 3834

[31] Sutton M A, Wolters W J, Peters W H, Ranson W F and McNeill S R 1983 Image Vis. Comput. 1133

[32] Lagattu F, Bridier F, Villechaise P and Brillau J 2006 Mater. Charact. 56 10-8

[33] Heripre E, Dexet M, Crepin J, Gelebart L, Roos A, Bornert M and Caldemaison D 2007 Int. J. Plast. 23 1512-39

[34] Moulart R, Rotinat R, Pierron F and Lerondel G 2007 Opt. Lasers Eng. 45 1131-47

[35] Scrivens W A, Luo Y, Sutton M A, Collette S A, Myrick M L, Miney P, Colavita P E, Reynolds A P and Li X 2007 Exp. Mech. 4763

[36] Kang J, Ososkov Y, Embury J D and Wilkinson D S 2007 Scr. Mater. $\mathbf{5 6} 999$

[37] Knauss W G, Chasiotis I and Huang Y 2003 Mech. Mater. 35217

[38] Jin H, Lu W-Y and Korellis J 2008 J. Strain Anal. Eng. 43 719-28

[39] Huang S F 2008 Strain 44

[40] Chen Z, Cotterell B and Wang W 2002 Eng. Fract. Mech. 69 597-603

[41] Beuth J L 1992 Int. J. Solids Struct. 291657

[42] Roland T, Feissel P and Brancherie D 2009 Proc. 19th Cong. Fr. Mec. (Marseille France)

[43] Hammacher J, Fuelle A, Flaeming J, Saupe J, Loechel B and Grimm J 2008 Microsyst. Technol. 141515

[44] Tijero M, Gabriel G, Caro J, Altuna A, Hernandez R, Villa R, Berganzo J, Blanco F J, Salido R and Fernandez L J 2009 Biosens. Bioelectron. 242410

[45] Tsuchiya T, Tabata O, Sakata J and Taga Y 1997 Proc. IEEE 10th Annual Int. Workshop on Micro Electro Mechanical Systems pp 529-34

[46] Sharpe W N Jr, Jackson K, Coles G, Eby M A and Edwards R L 2001 Mechanical Properties of Structural Thin Films (ASTM STP vol 1413) (Orlando, US: ASTM) pp 229-47

[47] Chasiotis I and Knauss W G 2000 Proc. SPIE-The International Society for Optical Engineering 4175 96-103

[48] Espinosa H D, Prorok B C and Peng B 2004 J. Mech. Phys. Solids 52 667-89

[49] Faurie D, Renault P-O, Le Bourhis E, Villain P, Goudeau P and Badawi F 2004 Thin Solid Films 469-70 (SPEC. ISS.) 201-5 